


\title{
El autorretrato literario en "José Coronel Urtecho siendo pintado por Dieter Masuhr o autorretrato con pintor": la colaboración dialógica entre el pintor, la pintura y el sujeto retratado ${ }^{1}$
}

\author{
A literary self-portrait in "José Coronel Urtecho painted by Dieter Masuhr or self-portrait with a \\ painter": dialogical collaboration among painter, painting and subject portrayed
}

\author{
Dorde Cuvardic Carcía ${ }^{2}$ \\ Recibido: 6/8/2016 / Aprobado:1/11/2016
}

\begin{abstract}
Resumen
A partir de un paradigma post-estructuralista, el ensayo José Coronel Urtecho siendo pintado por Dieter Masuhr o Autorretrato con Pintor, está analizado e interpretado en el presente documento. En este ensayo se incorporan importantes reflexiones sobre la comunicación dialógica -participativa y democrática-establecida entre el sujeto retratado y el pintor, durante el proceso creativo de este artista alemán. Por otra parte, el concepto de punto lacrimal, propuesto por Barthes para el campo fotográfico, y traducido al campo pictórico, nos ayuda a estudiar las reacciones subjetivas de José Coronel Urtecho, frente a su propio retrato antes de su finalización.
\end{abstract}

Palabras clave: Nicaragua Literatura, ensayo, las relaciones de la literatura-pintura, la representación pictórica, literaria autorretrato, la crítica a José Coronel Urtecho.

\section{Abstract}

From a Post-Structuralism paradigm, the essay José Coronel Urtecho siendo pintado por Dieter Masuhr o autorretrato con pintor is analyzed and interpreted in this paper. This essay incorporates important reflections on dialogic communication -participative and democratic- established between the subject portrayed and the painter, during the creative process of this German artist. Moreover, the concept of punctum, proposed by Barthes for the photographic field, and translated to the pictoric field, helps us to study José Coronel Urtecho's subjective reactions before his own self portrait -in constant change- prior to its finalization.

Key Words: Nicaraguan Literature, essay, literature-painting relations, ekphrasis, pictoric portrayal, literary selfportrait, criticism to José Coronel Urtecho.

\section{Introducción}

El retrato y el autorretrato no solo cuentan con una larga tradición en la práctica pictórica, sino también en la literaria. En esta última se han realizado dos tipos de retratos y de autorretratos, si se toman como eje los procedimientos descriptivos tradicionales utilizados, la etopeya -o descripción psicológica- y la prosopografía -o descripción física del individuo, incluido su comportamiento-. Estos géneros han participado tanto de las estéticas realistas (que buscan alcanzar el máximo efecto de realidad) como de las estéticas que tienen una intencionalidad satírica y utilizan la deformación grotesca.

\footnotetext{
1 Este texto corresponde con la temática de la ponencia presentada en el II Coloquuio Internacional de Investigación y Creación de la Cultura Artística Centroamericana, realizado el 9, 10 y 11 de setiembre de 2015, en el Museo Regional de San Ramón y en la Sede de Occidente, Universidad de Costa Rica, ahora en formato de artículo científico, en versión completa extendida. ${ }^{2}$ Doctor en Periodismo y Ciencias de la Comunicación, Magister en Literatura Española, profesor e investigador en la Escuela de Filología y Lingüística y en el Doctorado en Estudios de la Sociedad y la Cultura, Universidad de Costa Rica. Sede Rodrigo Facio. Correo electrónico: dcuvardic@yahoo.es
} 
En la práctica pictórica se pueden obtener retratos y autorretratos simples, dobles ${ }^{3}$ y triples ${ }^{4}$. En cambio, en el retrato literario no es posible representar el cuerpo dos veces mediante recursos verbales, a no ser que se use el perspectivismo espacial, como técnica de repetición descriptiva.

Los autorretratos, muy comunes en la práctica literaria, se practican más en la poesía que en la prosa. Muchos poetas cuentan con uno o varios autorretratos, escritos en distintas épocas de su carrera literaria ${ }^{5}$. Menos comunes son aquellos en los que se autorretratan en el ejercicio de la escritura, a diferencia de lo que ocurre en pintura. Y se está hablando solo de la simple mención a este último acto $^{6}$, el de escribir, sino también a la elaboración de un autorretrato sobre el proceso de la escritura lo más completo posible, que incorpore todas las decisiones y dilemas que constituyen el trasfondo, sobre todo ético, de la escritura (son numerosos estos autorretratos, eso sí, ya no en la poesía, sino bajo la 'máscara nominal' ofrecida por la novela autobiográfica).

Todavía menos comunes son aquellos textos en los que el escritor se autorretrata mientras otro artista, un pintor por ejemplo, se encuentra preparando su retrato, y que además utilice este último, el retrato pictórico, como signo mediador que le permita reflexionar sobre su propia identidad como sujeto. Este es el caso de "José Coronel Urtecho siendo pintado por Dieter Masuhr o autorretrato con pintor", texto ensayístico incorporado a Prosa reunida (1985), de José Coronel Urtecho (Granada, Nicaragua, 1906 - Managua, Nicaragua 1994), que se origina a partir de la situación comunicativa que pintor y poeta protagonizan -un encuentro, en el que el primero retrata al segundo-, y de la lectura personal que Urtecho realiza del retrato de Masuhr, que tiene por objeto de representación al escritor nicaragüense. Además de este texto ensayístico, Coronel Urtecho cuenta con un poema perteneciente al género del autorretrato, incorporado en su poemario antológico Pol-la D’Ananta, Katanta, Paranta (1970), que será trabajado ancilarmente a esta argumentación.

Se trata, sin lugar a dudas, de una situación poco común en los autorretratos literarios. En el presente caso, estrictamente, el escritor, en toda regla, no realiza un autorretrato, sino el retrato de su doble pictórico, elaborado por otro sujeto, un pintor.

\section{Fundamentación teórica}

A través de las reflexiones de un texto ensayístico, un escritor puede exponer, como en este caso, las reacciones subjetivas activadas a partir del retrato dedicado por un pintor. Las reacciones emotivas que la imagen fotográfica provoca en el observador han sido explicadas por Barthes (1989 [1980]) desde la categoría del punctum, cuya propuesta también se puede extrapolar a la comprensión de una pintura.

Por lo demás, tanto la pintura como la fotografía han sido estudiadas como configuradoras de la identidad, individual y colectiva. A través de una écfrasis ensayística, Coronel Urtecho procede a describir verbalmente un texto pictórico que lo retrata y que le permite exponer reflexiones sobre su identidad individual, familiar y nacional (nicaragüense).

El título es un programador de lectura (Genette, 2001) y esta función opera, asimismo, en el caso de los ensayos. "José Coronel Urtecho siendo pintado por Dieter Masuhr o autorretrato con pintor" expresa con precisión el contenido del ensayo, que remite, finalmente, a la producción

\footnotetext{
${ }^{3}$ Es el caso del pintor italiano del siglo XVI Parmigianino, gracias al uso de un espejo cóncavo.

${ }^{4}$ Es el caso del ilustrador del siglo XX Norman Rockwell. Se pueden consultar los siguientes libros para apreciar todas las posibilidades del retrato pictórico (realismo, vanguardia, postmodernismo): Rosa Martínez Artero, El retrato. Del sujeto en el retrato, Barcelona, Montesinos, 2004, y Ana María Guasch, Autobiografías visuales: entre el archivo y el índice, Madrid, Siruela, 2009. ${ }^{5}$ En el primer caso, piénsese por ejemplo, en Retrato, de Antonio Machado; en el segundo caso, en Adelfos y Retrato, de Manuel Machado.

${ }^{6}$ Así ocurre con la incorporación de la crisis de la hoja o de la página en blanco, en cuyo caso el escritor afirma carecer, ante el escritorio, de un tema de escritura
} 
artística visual desde un punto de vista dialógico. Se puede extrapolar, en consecuencia, la teoría dialógica de Mijaíl Bajtín (1983) a las artes visuales contemporáneas. Por una parte, el artista interacciona con su modelo, un escritor; por otra parte, el público, que cada vez se revela más -en el arte contemporáneo- como intérprete o productor, interacciona con el artista o con el texto visual, como ocurre con la colaboración entre el poeta nicaragüense y el pintor alemán. La producción artística se revela como un encuentro de subjetividades, como un acuerdo intersubjetivo.

El desdoblamiento del yo enunciativo ha sido un tema primordial de las artes plásticas figurativas en Occidente desde el Renacimiento, y sobre todo a partir de la estética simbolista -a finales del siglo XIX- en paralelo con las investigaciones freudianas sobre el inconsciente (Guasch, 2009; Martínez Artero, 2004). Coronel Urtecho, desde este presupuesto artístico, asume el retrato pictórico de Mashur como un doble con el que se identifica y se distancia.

\section{El encuentro entre artistas como texto ensayístico: reflexiones sobre un momento autobiográfico}

La situación descrita en este texto ensayístico es histórica, ya que tuvo lugar en 1983. El encuentro ocasional entre intelectuales y artistas, situación muy delimitada en el tiempo (solo se prolonga por varias horas, en ocasiones como tertulias, premiaciones, etc.), se ha llegado a incorporar tanto a la escritura biográfica -experiencias ajenas- como autobiográfica -experiencias propias-. A veces, la totalidad del texto del escritor llega a tematizar nada más que el encuentro producido, un episodio de la vida del escritor ${ }^{7}$. Una ocasión biográfica, en consecuencia, llega a definir un subgénero de la biografía: el 'encuentro entre intelectuales'. También es un encuentro la experiencia en la presente ocasión: un pintor retrata a un escritor y la pintura en proceso es aprovechada por este último para formular no sólo un retrato del artista que lo pinta, sino también para ejecutar su propio autorretrato literario.

El pintor con el que se relaciona Urtecho es el alemán Dieter Masuhr (1938- ), íntimamente ligado a la Revolución Sandinista, en cierto momento de su desarrollo. Durante su estadía en Nicaragua realizó retratos de algunas de sus personalidades políticas e intelectuales ${ }^{8}$. En 1983 prepara un retrato de grupo, de cuerpo entero, titulado Nueve poetas nicaragüenses (Neun nikaraguanische Dichter), elaborado en óleo sobre lienzo (200 por 630 centímetros), entre los que se encuentra, por ejemplo, Ernesto Cardenal. José Coronel Urtecho sería el primero en quedar retratado, como lo señala el propio escritor en el texto que analizamos, ya que en esta época residía en Costa Rica y permanecería por poco tiempo en tiempo en Nicaragua, donde se encontraba residiendo el pintor alemán. En el cuadro de Mashur, el escritor nicaragüense no queda retratado con una mirada frontal. Sus ojos miran, en actitud introvertida, hacia su derecha, como una prefiguración de las reflexiones identitarias que posteriormente integraría en su ensayo.

Este retrato colectivo, Nueve poetas nicaragüenses, recuerda la larga tradición de pinturas grupales definidas por el vínculo del oficio, como sucede con La ronda nocturna (16401642), de Rembrandt, encargo de una asociación de arcabuceros de Amsterdam. Los profesionales de los diferentes campos intelectuales y artísticos ocasionalmente se reúnen para quedar retratados en conjunto, ya sea pictórica o fotográficamente. También ocurre en la literatura, como es el caso de "La tertulia del café de Pombo" (1920), de José Gutiérrez Solana. José Coronel Urtecho es el primer poeta en posar para el cuadro de Masuhr y aprecia, cuando observa el proceso creativo de este último, la

\footnotetext{
${ }^{7}$ José Romera Castillo (2006: 179) ofrece dos ejemplos de encuentros entre el escritor y otra u otras personalidades: Mis almuerzos con gente inquietante (1984), de Manuel Vázquez Montalván, y Café y copa con los famosos (1990), de Fernando Vizcaíno Casas. ${ }^{8}$ Su obra pictórica realizada en Nicaragua se encuentra publicada en libros. Entre estos últimos, que recopilan su obra visual, se encuentra Los ojos de los guerrilleros: 87 dibujos hechos a quienes hicieron posible el triunfo de la revolución popular sandinista.
} 
elaboración de un retrato que todavía es individual y que, en aquellos momentos, no ha llegado a convertirse en colectivo.

Según Coronel Urtecho, no fue la primera vez en ser retratado. Afirma en el ensayo que ya fue retratado en tres ocasiones previas $^{9}$ por Antonio Rochi, por Peñalba (no da el nombre) y por una joven pintora (tampoco ofrece su identidad nominal). Declara el escritor nicaragüense (Coronel Urtecho, 1985: 246) que solo el rápido apunte con crayón realizado por esta última artista comparte con el retrato más elaborado que le realiza Masuhr, como se verá más adelante, la posibilidad de ver la huella de sus antepasados -de su linaje familiar- en la representación visual resultante.

\section{Análisis de "José Coronel Urtecho siendo pintado por Dieter Masuhr o autorretrato con pintor"}

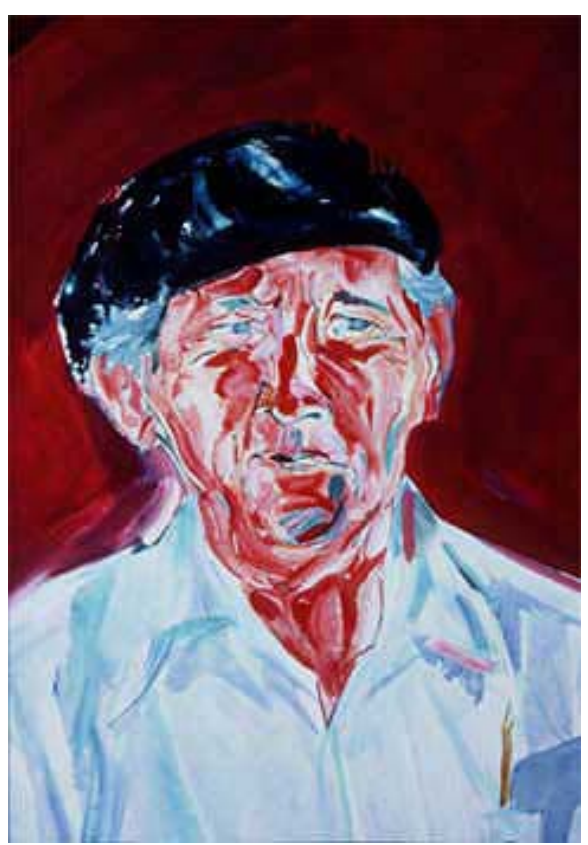

Sección de Nueve poetas nicaragüenses (Neun nikaraguanische Dichter), elaborado en óleo sobre lienzo (200 por 630 centímetros), 1983.

\section{Análisis del título como programador de lectura del ensayo}

Al acercarse al título de este ensayo, "José Coronel Urtecho siendo pintado por Dieter Masuhr o autorretrato con pintor", se comprende que ofrece algunos indicadores de su estructura general y de la intencionalidad del enunciador.

El hecho de que se utilice en el título la tercera persona (José Coronel Urtecho), en lugar de la primera ('yo') ya indica el distanciamiento identitario que se produce en las reflexiones que permean todo el texto. A su vez, al emplear el sintagma 'siendo pintado', Urtecho se refiere a la descripción de un proceso, de una experiencia, de un devenir, no de un resultado. 'Por Dieter Masuhr' señala, junto con el sintagma verbal, que en un principio el propio Coronel Urtecho ocupa durante esta experiencia (es decir, durante el proceso de pintar un retrato), el papel de objeto de la representación. Se trata de un proceso transitivo: un pintor retrata a un escritor.

En todo caso, esta perspectiva se invierte en la segunda parte del título: "autorretrato con pintor". El proceso transitivo, donde el poeta ocupa el papel de paciente, se sustituye por el autorreflexivo, donde la identidad de Coronel Urtecho se convierte en el objeto de reflexión y el pintor pasa a ocupar un papel subsidiario. Esta yuxtaposición de situaciones invertidas ('A siendo pintado por B', por una parte, y 'el autorretrato de B por B', por otra) no es una contradicción, lo que ocurrido es que el título ofrece, más bien, el plan general del ensayo, pues si bien las primeras páginas se ocupan de la experiencia o proceso de confeccionar un retrato, con Masuhr como protagonista, en la segunda mitad el centro de atención se orienta hacia el escritor, su biografía y la historia de sus ancestros, con la pintura no concluida como punto de apoyo.

\footnotetext{
${ }^{9}$ José Coronel Urtecho, “José Coronel Urtecho siendo pintado por Dieter Masuhr o autorretrato con pintor”, Prosa reunida, Managua, Nueva Nicaragua, 1985, p. 244-45. A partir de este momento, toda referencia al texto pertenece a esta edición.

${ }^{10}$ Esta versión del retrato (http://archivo.elnuevodiario. com.ni/nuevo-amanecer/302209- jose-coronel-urtecho-siendo- pintadodieter-masuhr-o- autorretrato-pintor/) no es la original analizada por el autor; sin embargo, coincide en todos los detalles. (http://leoneldelgadoaburto. blogspot.com/2006/07/jos- coronel-urtecho-1906-1994.html ya no está disponible)
} 
Primera parte del ensayo: el retrato de Masuhr y de su proceso creativo

La primera parte del ensayo retrata sobre todo al pintor alemán y la personalidad que exhibe durante la confección del retrato pictórico de Coronel Urtecho. Este artista queda definido, en este sentido, por su proceso creativo ${ }^{11}$. Si bien al final del ensayo Coronel Urtecho se interesa en su retrato, mientras Masuhr lo pinta, al principio, en cambio, se ocupa del pintor, de lo que hace y dice. En este sentido, las primeras páginas constituyen un retrato literario, el de un escritor sobre un pintor. Sobre todo, le sorprende la actitud asumida por el artista alemán durante el proceso de pintar su retrato: "Desde el primer momento, lo que más me llamó la atención fue no sólo que él hablara sino que trabajara con ironía." (243). Este es el principal atributo psicológico o etopéyico apreciado en el pintor alemán. Esa designación, trabajar con ironía, queda aclarada cuando, unas páginas más adelante, declara:

Trabajaba con mucha calma, con toda tranquilidad, con si no hiciera nada, como si recibiera una visita o sostuviera una sencilla conversación, mientras se entretenía jugueteando con un largo pincel, haciendo rayas y manchas, rayones y manchones en la tela clavada en la pared (248).

Es decir, opera el 'principio de negación' típico de la ironía, la anulación de las expectativas, la presencia de una 'aparente' contradicción. No observa a un artista ensimismado, quien lucha denodadamente por dar forma o cuerpo a una masa informe de pigmentos, a un pintor que intenta salvar la distancia o el abismo existente entre la idea y la materia. Se trata de una imagen estereotipada, por lo demás, del proceso productivo artístico. En cambio, logra apreciar la negación de este clisé. Ve a un artista, Masuhr, que no emplea, aparentemente, el menor esfuerzo físico e intelectual en su tarea.
Se espera de un pintor que trabaje en estado de exaltación, que de alguna manera indique las dificultades casi insalvables y los dilemas estéticos que le puedan 'asaltar' durante el ejercicio de su actividad artesanal, y no a un artista que ejecute su tarea en estado de tranquilidad.

Para los mismos escritores, el propio proceso creativo ha sido tipificado (se trata de un tópico o estereotipo literario) como una actividad inexplicable; es el caso de Shelley en su Defensa de la poesía, o de Bécquer, en su Introducción sinfónica o en algunas de sus Rimas, de ahí que no sea tan extraño que Coronel Urtecho asigne estas cualidades a otros artistas, aunque su radio de acción pertenezca a otra práctica significante, como es, en este caso, la pintura. Al escritor nicaragüense le sorprende la ausencia del furor creativo en el pintor. En principio, a los propios literatos se les ha atribuido esta imagen estereotipada del proceso productivo artístico y serían los primeros en evitar la proyección de esta imagen en los demás artistas, entre ellos los pintores. Para una persona lega, el proceso productivo artístico es entendido como una experiencia inefable, incomprensible, punto de vista que, paradójicamente y contra lo esperado, es asumido por Coronel Urtecho: "lo sucedido mientras me pintaba el pintor alemán, que apenas me conocía y menos a mi familia presente o pasada, me ha parecido inexplicable."(246).

El punto de vista de Coronel Urtecho no responde a la aplicación de un estereotipo, responde más bien a la intención de dignificar un arte equivalente, la pintura. Si el escritor nicaragüense considera el acto de pintar como una actividad misteriosa, esta apreciación tópica se entiende mejor cuando se asume como un homenaje, como un elogio de un artista hacia otro. Sobre todo, le 'sorprende' a Coronel Urtecho el establecimiento de un orden a partir del caos, que se puedan organizar signos icónicos a partir de los signos plásticos, de la misma forma que para los poetas es incognoscible,

\footnotetext{
${ }^{11}$ Se sintetiza el objetivo de esta primera parte cuando Coronel Urtecho afirma, al inicio del texto, que durante su desarrollo se referirá "al que me pinta, a lo que él haga o diga o lo que yo descubra en él mientras me pinta, dentro de la experiencia básica de este escrito, que no es otra que la experiencia de ser pintado por Dieter Masuhr." (244)
} 
según el tradicional tópico literario, el trasvase de las ideas poéticas a la expresión formal del poema ${ }^{12}$. El escritor nicaragüense afirma que carece de criterios para interpretar causalmente el surgimiento de la forma orgánica pictórica, a partir de la 'materia significante', una problemática que ha ocupado a los poetas en relación con lenguaje, su propia materia prima:

Todo, efectivamente, se integraba a la totalidad, en una forma orgánica, necesaria y al mismo tiempo libre y predeterminada, como parece suceder en la naturaleza. Yo no podía ni seguir ni juzgar ni el valor ni el sentido de las al parecer inarticuladas, insubordinadas, incomponibles, anárquicas pinceladas, limitándome sólo a mirarlas caer y amontonarse sobre la superficie de la tela como copos de nieve color de sangre, la legendaria nieve color rojo sangre y color carne viva que misteriosamente iban formando la cara y las manos de mi retrato (249).

Eso así, Coronel Urtecho, como poeta, no puede dejar de reconocer que frente al ingenio natural, frente al genio (las primeras páginas constituyen un panegírico del pintor alemán) que actúa sin plan y obtiene sin esfuerzo sus resultados artísticos, se esconde un proceso creativo totalmente planificado. De hecho, utiliza el sintagma forma orgánica necesaria -como se lee en la cita precedente- para hablar del retrato de Masuhr. 'Forma orgánica' es, finalmente, una metáfora biológica (estructuralista) ya usada por Platón, Aristóteles y Horacio para referirse a la coherencia de la obra artística, a la homología entre forma y contenido. Por este motivo, aunque el pintor le informa a Coronel Urtecho sobre la aleatoriedad o ausencia de planificación, predominante en su proceso creativo -"me dijo que sus pinceladas eran abstractas, o más bien abstracciones, hechas como al acaso, pero por una secreta necesidad y su propio valor o significado particular" (249)- este argumento no le termina de convencer al escritor nicaragüense y formula una hipótesis alternativa -"sospecho que él todo lo hace deliberadamente, dándose exacta cuenta de todo lo que hace y hasta haciéndolo todo con premeditación." (249). Coronel Urtecho reconoce que Masuhr se encuentra sujeto, como todo artista creativo (escritor, pintor), a una técnica, a un arte, a unas habilidades y competencias adquiridas durante un proceso de aprendizaje. Se aleja, por lo tanto, del tópico del proceso creativo como una experiencia inefable.

\section{Segunda parte del ensayo: el proceso creativo como un proceso dialógico}

Muy importante en la interpretación que tiene Coronel Urtecho de la pintura es su comprensión de esta práctica artística como una actividad dialógica. Emplea los términos conversación y colaboración. Mashur, durante su desempeño como pintor, incentiva, según Coronel Urtecho, que el sujeto retratado intervenga durante el proceso creativo:

Dieter Masuhr no hace retratos, o no sé que los haga, como suelen hacerlos otros pintores que he conocido, asignando al que van a pintar el papel de 'modelo', como dicen los del oficio, es decir, objetivándolo o separándolo de su imagen subjetiva o de su identidad existencial, inmovilizándolo en un lugar determinado, tal como lo estará ya pintado en el cuadro, sino como ya dije, asociándolo a su propio trabajo, a su propia creatividad, y hasta haciéndolo en lo posible colaborar en la creación de su propio retrato. Hasta pudiera quizá decirse que el retrato de uno por Dieter Masuhr es en alguna medida autorretrato. El retratado por Dieter Masuhr deja de ser modelo en el sentido convencional y se convierte hasta cierto punto en autor o coautor de su retrato. No sólo por un proceso de identificación o de empatía con el pintor, sino también por una especie de proyección de su imagen subjetiva o su autoimagen en

\footnotetext{
${ }^{12}$ Esta es una clásica manifestación de las metáforas continente-contenido: el poema es el continente y las ideas poéticas el contenido.
} 
la que va pintando el pintor en un cuadro. [...] Todo retrato auténtico, aun el hecho por medio de una cámara fotográfica, debe ser el efecto de una conversación, cuando no es, como a veces ocurre, el testimonio de una confesión.(245-247).

Coronel Urtecho tiene una comprensión dialógica del proceso comunicativo de la producción artística, por eso identifica el retrato como una "dialéctica" (252). No solo se puede hablar de la estructura dialógica del texto verbal, tema del que se han ocupado Bajtín (2003) y Voloshinov (1992), sino también de una comprensión dialógica de la producción artística visual. De la misma forma que, en la comunicación verbal, el discurso propio se va modificando a partir de la incorporación paulatina de la perspectiva ideológica ajena, durante el proceso creativo, el pintor (en este caso Masuhr) transforma el retrato de Coronel Urtecho a partir de la incorporación de lo que considera la subjetividad de la persona retratada. Coronel Urtecho utiliza el plural al señalar que "trabajábamos o pintábamos" el retrato (252).

La ubicación del pintor y del sujeto retratado, la relación espacial entre ambos, incentiva este diálogo dialógico, ya que Masuhr no sitúa al retratado detrás del lienzo, bajo el control visual panóptico del artista, sino que ambos se disponen cara a cara frente a la pintura:

Al retratado no lo coloca este pintor como los de antes, enfrente de él de cara a él, a una cierta distancia, con el cuadro en su caballete entre ambos participantes, pintor y pintado, puesta esa especie de atril de tal manera que el pintado sólo vea lo de atrás de la tela, mientras el lado de la pintura únicamente el que lo pinta lo tenga a la vista, salvo si este consiente que aquél llegue a asomarse, lo que muy raramente sucede antes de que el retrato se dé por terminado. (253)

Coronel Urtecho destaca que el pintor alemán, por el contrario, lo invita a estar a su lado mientras pinta. Ambos contemplan la tela desplegada en la pared y conversan sobre la pintura en proceso, en constante transformación:
Dieter Masuhr te invita a quedarte de pie a su lado, a la par de él, igual que un par de amigos que se entretienen conversando y contemplando al mismo tiempo un cuadro de tela clavado en la pared, en el que el uno va a pintar o está pintando al otro, o los dos ellos, como ya dije, están colaborando en el trabajo que de algún modo van haciendo juntos, hablando de ello y de ellos mismos, interpretando o descifrando lo que va apareciendo en la tela de enfrente, como resultado imprevisto de las pinceladas, al parecer casuales, del que oficia como pintor. (253)

Coronel Urtecho define el encuentro con Masuhr como una colaboración mutua, como un proceso realizado por dos sujetos, donde ambos planifican, ejecutan y evalúan la producción artística durante la marcha. La pintura se convierte en el resultado de un encuentro intersubjetivo.

Tercera parte del ensayo: Urtecho interpreta semiótica e identitariamente el retrato que le prepara Masuhr

El retrato provoca en el retratado (en Coronel Urtecho) un efecto de distanciamiento, de objetivación. Como parte de esta actitud de extrañamiento, intenta asumir el papel de crítico de arte: procede a realizar una écfrasis, una descripción literaria de una obra de arte pictórica (su retrato), pero no de una pintura terminada, sino del proceso de su elaboración. Por lo tanto, se trata de una écfrasis en la que se realizan constantes intentos descriptivos y evaluativos. Coronel Urtecho plantea afirmaciones que rápidamente desecha, así como propone distintas vías de interpretación sobre el proceso creativo de Masuhr, sobre las que no toma una decisión terminante (de ahí el constante uso de la conjunción 'o'). Este pensamiento, no concluyente, se encuentra en perfecta sintonía con el género utilizado por el escritor nicaragüense: el ensayo.

Coronel Urtecho se interesa por los signos plásticos, y sobre todo por el color, específicamente por el rojo, como medio expresivo que permite 'materializar' la carne. La exhibición de la pintura 
como 'carne' (o la condición 'carnal' del color y la textura de sus cuadros), el procedimiento de destacar la materia expresiva o el soporte plástico (el color) que contiene en sí mismo el signo figurativo (en este caso, la piel), emparenta a Masuhr con Francis Bacon y Lucien Freund. Coronel Urtecho no presta atención al cuadro como signo figurativo (su condición más o menos realista, en relación con su referente), sino más bien a la materia expresiva -los colores- que constituyen su soporte. Este interés en el 'hacerse' y no en el producto terminado tiene claras implicaciones identitarias: la identidad no es una esencia que se pueda fijar en una representación terminada (el cuadro concluido), sino que es un constante proceso que encuentra su más pertinente alegoría en un retrato en constante transformación, como el de Masuhr, desde las primeras pinceladas rojas en bruto, que Coronel Urtecho identifica semánticamente con su propio nacimiento, hasta que unas nuevas pinceladas, aplicadas por el pintor sobre el lienzo, le permiten atisbar su adolescencia y su etapa adulta (258). Desde este presupuesto, se trata de una pintura que no solo deconstruye las convenciones del retrato pictórico, sino también las del autorretrato literario, ya que ambos se interpretan como procesos.

Urtecho, sobre todo, se interesa por los significados ideológicos del signo plástico, más que del figurativo, al que tradicionalmente se asocia el género del retrato:

No sé si en realidad, el color carne viva de los retratos hechos por él en Managua, lo usa Dieter Masuhr con intención simbólica. De todos modos pudiera ser símbolo de violencia [...]. Esos estados emocionales o realidades pasionales los encontró ya entre nosotros, que aún los seguimos heredando de la conquista y a través de la explotación. [...] Nada extraño sería que el color rojo sangre o el color carne viva fueran vistos por él como variantes del cobrizo indígena, nuestro color racial o natural y tal vez a la vez real y simbólico. (249)
Como se puede observar, los signos plásticos, y no los figurativos, quedan investidos de valores connotativos, como es la historia personal o la identidad étnica del sujeto retratado. En su argumentación, el escritor nicaragüense incluso otorga, en un caso de resemantización, una valencia positiva (en el sentido de mestizaje) al término cobrizo, utilizado por las teorías racistas eurocéntricas para designar a todos aquellos sujetos que, desde su perspectiva, no quedaban integrados en las razas 'blanca', 'negra' o 'amarilla'.

Trasladando su aplicación inicial del ámbito fotográfico al pictórico, podríamos afirmar que la lectura realizada por Coronel Urtecho de su propio retrato se interesa por el punctum, si recuperamos el término de Barthes (1986). La interpretación del escritor nicaragüense se aleja de los tradicionales valores ideológicos asignados por el espectador al signo icónico. El signo plástico (el rojo, símbolo de la carne) es interpretado como una serie de capas que expresan la memoria familiar del retratado, a la que se dedican las últimas páginas del ensayo: “Toda esa gente pasó de algún modo, sin saber yo ni cómo y hasta quizá ni cuando, por las facciones de mi retrato en el proceso de ser pintado por Dieter Masuhr, sin que él tuviera, desde luego, ni el más ligero indicio de lo que sucedió" (270). Una de las posibilidades ofrecida por la lectura de la fotografía desde el punctum, señala Barthes (1986: 177), en reflexiones que también se pueden otorgar a la recepción de un retrato pictórico, es identificar el linaje que se esconde detrás del sujeto retratado: "[A]lgunas veces la Fotografía hace aparecer lo que nunca se percibe de un rostro real (o reflejado en un espejo): un rasgo genético, el trozo de sí mismo o de un pariente que proviene de un ascendiente. La Fotografía ofrece un poco de verdad, con la condición de trocear el cuerpo. Pero dicha verdad no es la del individuo, que sigue siendo irreductible; es la del linaje." La consideración del retrato como archivo de la memoria personal y familiar no involucra al pintor, a la instancia autorial, sino al observador, que en este caso es el propio retratado, es decir, a Coronel Urtecho. Se trata de un retrato vivo, que se transforma constantemente. La 
metamorfosis de su materia plástica y figurativa implica su metamorfosis semántica (en cada fase de su preparación, la pintura le permite actualizar parte de su memoria familiar). Cada nueva pincelada, sobreimpuesta a la precedente, es un palimpsesto que le permite a Coronel Urtecho recordar nuevas capas de su pasado.

Una vez terminado, el retrato se convierte en un palimpsesto 'cinematográfico' que guarda huellas de todos sus orígenes étnicos: "Esto se producía en una rapidísima sucesión de fisonomías o parecidos como en una película cinematográfica que tratara de presentar una muchedumbre, desfilando o transitando simultáneamente por una sola cara." (263). Aquí se presenta una analogía vigente desde hace un siglo. Los 'recuerdos' se comprenden como una 'película' que se despliega ante los ojos del espectador: la sucesión de las imágenes mentales recordadas se interpreta como la sucesión de los fotogramas de una película. Diversos escritores emplean esta analogía desde los inicios del siglo $\mathrm{XX}$, como el cronista guatemalteco Enrique Gómez Carrillo, en una de sus crónicas sobre la retaguardia en los campos de la primera guerra mundial ${ }^{13}$, José Ortega y Gasset, en el ensayo Azorín o los primores de lo vulgar (1917) ${ }^{14}$, o Rubén Darío, en el "Prólogo" a Crónicas del bulevar (1903) ${ }^{15}$.

El retrato que le pinta Masuhr es, para Coronel Urtecho, un 'doble vivo'. El poeta nicaragüense experimenta el sentimiento de lo ominoso, de lo siniestro, ante su propio retrato. Asimismo, una de las poetas que posteriormente vio el retrato de Coronel Urtecho pintado por Masuhr, una vez terminado, señaló haber sentido miedo ante la representación pictórica (275). Esta apreciación también debe ponerse en relación con el corto poema "Autorretrato", del poeta nicaragüense, que aparece en la sección Varia de POL-LA D'ANANTA, KATANTA, PARANTA, ya que habla de la activación de la misma emoción, la del miedo, ante la observación del doble: "Cuando al mirarme en el espejo/ Veo en mi cara la de mi padre /Absurdamente tengo miedo." (1970: 186). En este último caso, el doble icónico no procede de una pintura, sino de un espejo, pero las consecuencias de la mirada sobre el doble 'objetivado', sobre la duplicación, son las mismas: tanto en el ensayo como en el poema se produce una experiencia ominosa, desfamiliarizadora. Pero el poema y el ensayo también guardan otro punto en común. En ambas oportunidades, Coronel Urtecho no solo reconoce en la imagen a un doble icónico, sino asimismo la capacidad de este último de expresar todos los vínculos familiares que la identidad individual ha reprimido. Así, por ejemplo, en el poema, el enunciador vislumbra en su propia imagen, observada en el espejo, la de su propio padre. Se plantea la siguiente hipótesis: el linaje, como condición identaria 'viva' de todo ser humano, es tema recurrente en la obra de Coronel Urtecho.

Un mito universal plantea que toda imagen figurativa es un doble identitario que llega a tener una vida independiente frente al sujeto retratado.

\footnotetext{
${ }^{13}$ Enrique Gómez Carrillo, cuando deambula por la ciudad belga de Iprès, convertida en escombros en la I Guerra Mundial, al recordar su anterior visita a la ciudad, antes de su destrucción, utiliza el cine, que apenas tenía veinte años de existencia, como metáfora de los recuerdos, procedimiento retórico ya consolidado en la actualidad bajo el enunciado de 'veo pasar la película de mi vida. En el caso del cronista guatemalteco, declara que "como en un cinematógrafo, pasan por mi memoria las fachadas ilustres de la rue de Lille..." (Gómez Carrillo, 1922: 126).

${ }^{14}$ Ortega y Gasset, por su parte, integra esta metáfora en su reflexión sobre la situación de ruina espectral en la que, considera este filósofo, se encontraba España a inicios del siglo XX. El cinematógrafo se utiliza como metáfora ontológica que permite conferir condición material a las imágenes de los recuerdos: “Imagínese que el mundo entero sucumbiera y quedara sólo una conciencia y en ella el poder de recordar. El mundo sido volvería a desarrollarse una y otra vez, en todos sus detalles, como la película de un cinematógrafo, dentro de aquel escenario espiritual. Volvería todo; pero volvería exangüe, imaginario, espectral. Así nuestra patria." (Ortega y Gasset, 1957: 173).

${ }^{15}$ En este último caso, siete años después de la invención de cinematógrafo, quedan identificadas las impresiones de la cámara con las del transeúnte: "París se llama Legión y Legiones; su multiplicidad no admite cánones; su abarcamiento exigiría vidas y vidas. Hay que ser veloz y vivaz para asir al vuelo tanta variedad. La observación debe ser cinematográfica. Quien pretenda señalar esta cualidad como un defecto en los que escribimos en los diarios, no está con la razón. Se puede ser ligero como el aire, y llevar el polen fecundador."(Darío, 2003: 101).
} 
La interpretación animista de la imágenes considerar que estas últimas tienen vida propia- es una experiencia que el proceso de la civilización ha reprimido (Freedberg, 2009); se puede plantear que observar un retrato 'en su hacerse' - como le ocurre a Coronel Urtecho- incentiva en el retratado el distanciamiento, el extrañamiento, la certidumbre de enfrentarse a un doble con vida. Es una experiencia reprimida -la animista- que de pronto se hace familiar, evidente. De ahí que en lugar de utilizar el pronombre personal 'yo', usa su identidad nominal, en tercera persona, al describirse a sí mismo en el cuadro; se asume como objeto de reflexión. Asimismo, se refiere en otras ocasiones a la 'acción de incorporarme a la pintura', de 'extraerme de mí mismo', 'de ponerme en su cuadro', en el de Masuhr.

Propone un pseudónimo para el retrato que Masuhr le ha confeccionado: el desollado. Considera que el pintor alemán exhibe todas las capas identitarias del sujeto retratado a medida que, gracias a la manipulación del color, se incorporan nuevas capas de pintura al retrato. Las capas de color son, por analogía, capas de 'piel' que le van desnudando -es decir, desollando- en su identidad. La pintura en proceso le permite a Coronel Urtecho recuperar su memoria familiar, es decir, 'desuella' la historia de sus antepasados. Por eso debe entenderse el 'desuello' como 'desenmascaramiento', como medio de legitimar el linaje que había olvidado. El texto, en esta sección, se convierte en una autobiografía familiar. Solo al identificar a sus antepasados apreciará en el retrato su identidad como sujeto. Desde la tercera persona, se autodesigna como "el desollado del retrato, un nicaragüense como otro cualquiera al que la revolución ha desnudado de su piel de su vieja oveja piel y se ha quedado sin piel de lobo, no piel de oveja. Ya tal vez sin rapacidad, sin miedo y sin hipocresía." (251).

Desollar supone rechazar todos los disfraces, todas las máscaras e imposturas (políticas, artísticas) y reconocer sus raíces, familiares y populares, al mismo tiempo. Comienza a identificar a sus antepasados cuando el retrato toma su primer perfil figurativo: “[E]l retrato empezó a definirse como mío y tomar de algún modo los rasgos de mi cara y mi modo de estar, el aire de mi figura" (259). En primer lugar, realiza un recorrido por sus antepasados judíos, de los que procede su apellido Coronel; seguidamente, identifica la 'presencia', en el retrato y en su propia identidad, de los antepasados indígenas (los Cabistán y los Zúñigas). Cuando, hacia el final del ensayo, afirma que el retrato de Dieter Masuhr se parece a él más que él mismo, que su imagen es 'él', aunque más permanente, más definitiva, más intemporal (273), se puede interpretar como signo visual que cumple la función de depósito de la memoria familiar, puntal ineludible de toda identidad personal.

\section{Conclusiones}

Desde el género del ensayo "José Coronel Urtecho siendo pintado por Dieter Masuhr o autorretrato con pintor" es un autorretrato (de un escritor) y un retrato (de un pintor y de su trabajo). Como texto ensayístico, consiste en una serie de tentativas interpretativas. No define, sino que trata de explicar, la disposición desde la que Coronel Urtecho logró encarar el desempeño del pintor alemán, mientras este último elaboraba su retrato. De ahí que abunden las tentativas de entender un proceso (pintar) y un producto (la pintura).

Como autorretrato, este texto adopta una estrategia posestructuralista: José Coronel se autoenajena frente al retrato. Lo considera una 'materia viva' que le permite sacar a la luz el pasado familiar que tenía reprimido u olvidado. Solo en escasas ocasiones se habla, en el autorretrato literario, de diversidad identitaria (cuando, en términos etopéyicos, el enunciador formula una doble o triple identidad psicológica, cuya estabilidad se encuentra constantemente diferida). Esta es la principal contribución del texto de Coronel Urtecho a la historia de los autorretratos literarios. ¿Qué intenta explicar? El proceso creativo del pintor, las identidades y las asociaciones nemotécnicas activadas por su retrato pictórico... El cuadro que pinta Masuhr es, desde el punto de vista del destinatario e intérprete de la imagen, un retrato que expresa una identidad colectiva, ya que en él no solo se identifica a sí mismo, sino también todo su linaje familiar. 
El concepto del punctum permite comprender la ilusión corporal y nemotécnica que, según el observador (en este caso, Coronel Urtecho), se desprende del retrato de Masuhr. El punctum se refiere a aquel componente de la fotografía que desencadena una reacción emotiva en el observador. En La cámara lúcida (1989), Barthes reflexiona sobre el poder que tiene este medio de conferir vida a lo desaparecido, de hacer presente lo ausente, de demostrar que algo ha existido. El observador, de manera ilusionista, se remonta en el tiempo, hacia el pasado, hacia el momento en el que tuvo lugar el acto fotográfico; otra reacción que puede provocar la foto es crear la ilusión de que la persona fotografiada se remonta en el tiempo y se proyecta hacia el presente, hacia el momento en el que el observador mira la fotografía.

La dialéctica entre la vida y la muerte, entre la presencia y la ausencia, es típica del signo icónico y se encuentra en muchos textos que tienen como tema de reflexión la observación de una pintura o una fotografía. En el caso particular del escritor nicaragüense, la pintura de Masuhr le permite remontar el pasado, su memoria familiar, y de proyectarla al presente. Se considera así que Coronel Urtecho, al ser retratado, se formuló las mismas preguntas que se plantea el pensamiento posestructuralista. Obtuvo respuestas similares: su retrato, durante el proceso de su elaboración por Dieter Mashur, le propuso problematizar la 'esencia' de su propia identidad. Obtuvo una respuesta inesperada: se percató del carácter fragmentario, en proceso y culturalmente híbrido, de su identidad.

\section{Bibliografía}

Bajtín, M. (2003). Problemas de la poética de Dostoievsky. México: Fondo de Cultura Económica.

Barthes, R. (1986). Lo obvio y lo obtuso. Imágenes, gestos, voces. Barcelona: Editorial Paidós.

Barthes, R. (1989). La cámara lúcida. Nota sobre la fotografía. Barcelona, Editorial Paidós.

Coronel, J. (1985). “José Coronel Urtecho siendo pintado por Dieter Masuhr o autorretrato con pintor". En: Prosa reunida. Managua: Nueva Nicaragua, 243-275.

Coronel, J. (1970). POL-LA D'ANANTA, KATANTA, PARANTA. León, Nicaragua: Universidad Nacional Autónoma de Nicaragua, 1970.

Darío, R. (2003). Prólogos (Recop., introd. y notas de José Jirón Terán). Managua, Nicaragua: Academia Nicaragüense de la Lengua.

Freedberg, D. (2009). El poder de las imágenes (2da. edición). Madrid: Cátedra.

Genette, G. (2001). Umbrales. México: Siglo XXI.

Gómez, E. (1922). El quinto libro de las crónicas. Madrid: Mundo Latino.

Guasch, A. (2009). Autobiografías visuales: entre el archivo y el indice. Madrid: Siruela.

Lotman, I. (2000). "El retrato". En: La semiosfera III. Madrid: Cátedra.

Martínez Artero, Rosa. (2004). El retrato. Del sujeto en el retrato. Barcelona: Montesinos.

Romera, J. (2006). De primera mano. Sobre escritura autobiográfica en España (Siglo XX). Madrid: Visor.

Senabre, R. (1997). El retrato literario (Antología) (Comp. e introducción). Salamanca, Ediciones Colegio de España.

Voloshinov, V. (1992). El marxismo y la filosofía del lenguaje. Madrid: Alianza Editorial. 